\title{
HL7 Clinical Laboratory Risk Engine Alerts in Hospitalized
}

\section{Patients}

\author{
Humberto Fernán Mandirola Brieux ${ }^{1,2,3,4}$, Fernando Campos ${ }^{1,2}$, Diego Kaminker ${ }^{2}$, Sebastian Guillen ${ }^{3}$, Fernando La Rosa ${ }^{2}$ \\ ${ }^{1}$ Health Informatics Department, Hospital Italiano de Buenos Aires, Argentina (HIBA) \\ 2 HL7 Argentina \\ 3 BIOCOM Argentina \\ ${ }^{4}$ Hospital Belgrano Buenos Aires Argentina
}

\begin{abstract}
The objective of the study is to assess a HL7 clinical laboratory risk alert System in hospitalized patients versus the conventional methodology.

Method: We studied laboratory tests administered to 300 medical patients in the Belgrano Hospital intensive care unit. We considered two groups of 150 patient tests. In the first the group (control group), clinical laboratory risk was diagnosed in a traditional way. In the second group (alarm group), clinical laboratory risk was diagnosed with an alert system. The alert was triggered when a patient showed low or high levels of any of the following variables: blood glucose, hematocrit, WBCs, arterial blood gases, blood urea, blood creatinine, blood sodium and blood potassium.
\end{abstract}

Results: Clinical laboratory risk was detected in 20.3\% of the control group patients of tests while, in the alert group, clinical laboratory risk was detected in $34.3 \%$ of the patients tests; the difference between the two groups was significant $(p<0.001)$, with a sensitivity rate of $99 \%$ and a specificity rate of $98 \%$.

Conclusion: Clinical Laboratory risk is more easily detected when using an alert system.

\section{Keywords}

Clinical laboratory risk alert; HL7; informatics system; critical values; alert values; critical values reporting

\section{Correspondence to:}

Humberto Fernán Mandirola Brieux

HL7 Argentina

Address: Amenabar 1645, ciudad de Buenos Aires, Argentina

E-mail: hmandirola@gmail.com

EJBI 2016; 12(1):en58-en61

received: April 19, 2016

accepted: April 30, 2016

published: May 20, 2016

\section{Introduction}

In the intensive care unit (ICU) it is important to monitor certain laboratory variables, often several times a day.

In previous studies we have found that alerts are useful in the ICU. 1]

The importance of the data obtained is such that significant changes or unusual values should be communicated immediately to the health personnel in charge. All staff must know how to recognize and interpret these critical values 2, 3 ,

Physicians are faced with the task of comprehending and acting on a rising flood tide of information. It is therefore important that systems be in place to help them monitor laboratory results. 4]

Several studies show the importance of controlling the exchange of information to the delivery of care on all levels of the health care delivery system - the patient, the care team, the health care organization, and the encompassing political-economic environment. [5]

Effective clinical alarm management relies on designs that promote appropriate use, clinicians who take an active role in learning how to use equipment safely over its full range of capabilities, and hospitals that recognize the complexities of managing clinical alarms and devote the necessary resources to develop effective management schemes. [6]

There is no particular alarm message standard to HL7 version 2.5; however, there is one in HL7 version 2.6. There is an IHE profile that defines the entire infrastructure (actors, responsibilities) to manage alarms. Specifically used as an alarm message: the ORU ${ }^{\wedge} \mathrm{R} 40$ form HL7 v2.6 (7.3.12 ORU - Unsolicited Alert Observation Message) (Event R40) [7, 8, 9] 


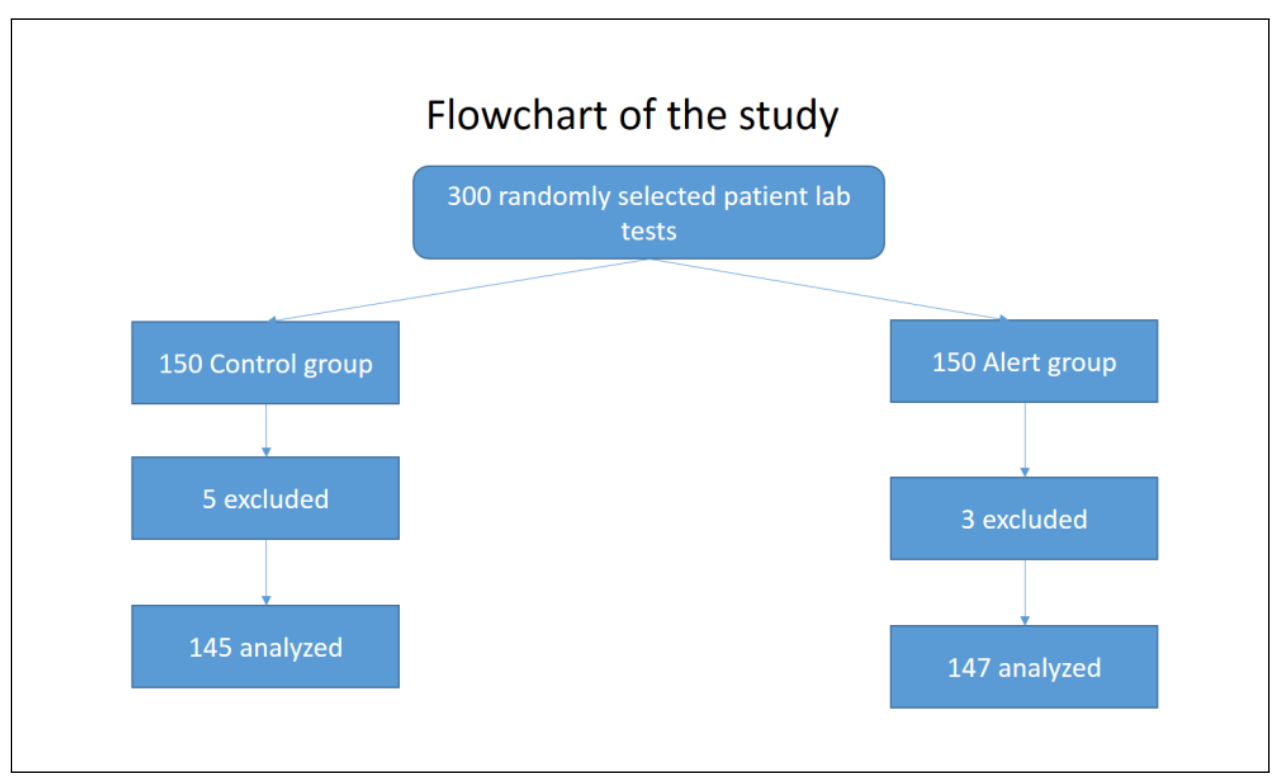

Figure 1: Flowchart of the study.

Several tools have been developed in the field of health care using data and information systems systematically; making decisions on the basis of the best available peer-reviewed evidence; applying program-planning frameworks (often based in health-behavior theory). 10

Occasionally, the importance of the data obtained requires immediate communication with the health personnel in charge. All laboratory staff must know how to recognize and act on these critical values. 11, 12

We think a clinical laboratory risk alert on laboratory values outside particular ranges is better than sending the data via an HL7 interface from the LIS system to the EHR, so we did a study to measure the efficacy.

Objective: The objective of this study is to prove that an alert is a helpful tool for doctors to better detect clinical laboratory risk in hospitals. This was a randomized experiment study with a control group. This research was carried out in the Belgrano Hospital ICU, where patient data were gathered in a sequential manner. We worked with two groups of patients: the control group and the group in which an alert was utilized.Although all the doctors were informed about the study beforehand, both groups of doctors who attended these patients carried out their tasks in the usual way during the study, and only the doctors who attended patients in the alert group were informed if patients had values above or below normal in the following variables: blood glucose, hematocrit, WBCs, arterial blood gases, blood urea, blood creatinine, blood sodium and blood potassium over or under normal values. The 8 -bed unit is staffed by 10 physicians and 20 nurses and discharges an average of 32 patients per month. The total starting sample consisted of 300 patient laboratory tests.

We selected 300 laboratory tests performed on patients treated at the Belgrano Hospital intensive care unit who were hospitalized between November 1, 2015, and Decem- ber 20, 2015. These patient tests were divided into two groups through routine random number generation. In the control group, clinical laboratory risk was detected in the traditional way, while in the alert group, clinical laboratory risk was detected with the help of an automatic alert system. (Figure 1)

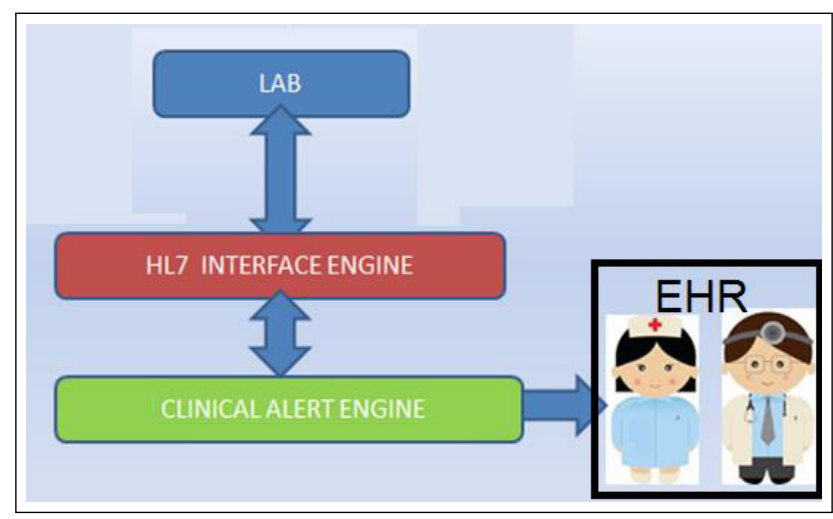

Figure 2: How the alert engine works.

The criterion standard was created by a committee of experts who retrospectively analyzed all the information available in the medical records in order to determine which patients in both groups were at clinical risk.

Inclusion criteria: Patients who underwent blood glucose, hematocrit, WBCs, arterial blood gases, blood urea, blood creatinine, blood sodium and blood potassium tests. Deceased patients were also included.

Exclusion criteria: Patients who did not undergo lab tests were excluded from this study.

The Alert engine use the standard Health Level Seven International (HL7). The alert is triggered when a patient shows low or high levels of the following variables: blood glucose, hematocrit, WBCs, arterial blood gases, blood 


\begin{tabular}{|c|c|c|c|c|c|c|}
\hline LOINC code & Sex & variables & Over & Under & Unit & Alert Message \\
\hline $5792-7$ & B & blood glucose & 0 & 70 & $\mathrm{mg} / \mathrm{dL}$ & Low blood sugar \\
\hline $5792-7$ & B & blood glucose & 100 & 1000 & $\mathrm{mg} / \mathrm{dL}$ & High blood sugar \\
\hline $4544-3$ & $\mathrm{M}$ & hematocrit men & 0 & 38 & $\%$ & Low hematocrit \\
\hline $4544-3$ & $\mathrm{M}$ & hematocrit men & 50 & 100 & $\%$ & High hematocrit \\
\hline $4544-3$ & $\mathrm{~F}$ & hematocrit woman & 0 & 34 & $\%$ & Low hematocrit \\
\hline $4544-3$ & $\mathrm{~F}$ & hematocrit woman & 44 & 100 & $\%$ & High hematocrit \\
\hline $57021-8$ & B & WBCs (white blood cells) & 0 & 4500 & per mc & Low WBC \\
\hline $57021-8$ & $B$ & WBCs (white blood cells) & 10000 & $1 \mathrm{E}+05$ & per $\mathrm{mc}$ & High WBC \\
\hline $3094-0$ & B & blood urea & 0 & 7 & $\mathrm{mg} / \mathrm{dL}$ & Low blood urea \\
\hline $3094-0$ & B & blood urea & 20 & 100 & $\mathrm{mg} / \mathrm{dL}$ & High blood urea \\
\hline $2160-0$ & $\mathrm{~B}$ & blood creatinine & 0 & 0.6 & $\mathrm{mg} / \mathrm{dL}$ & Low blood creatinine \\
\hline $2160-0$ & B & blood creatinine & 1.2 & 10 & $\mathrm{mg} / \mathrm{dL}$ & High blood creatinine \\
\hline $1959-6$ & $\mathrm{~B}$ & blood sodium & 0 & 135 & $\mathrm{mEq} / \mathrm{L}$ & Low blood sodium \\
\hline $1959-6$ & B & blood sodium & 145 & 200 & $\mathrm{mEq} / \mathrm{L}$ & High blood sodium \\
\hline $2823-3$ & B & blood potassium & 0 & 3,5 & $\mathrm{mEq} / \mathrm{L}$ & Low blood potassium \\
\hline \multirow[t]{2}{*}{$2823-3$} & $\mathrm{~B}$ & blood potassium & 5 & 10 & $\mathrm{mEq} / \mathrm{L}$ & High blood potassium \\
\hline & & Arterial blood gases & & & & \\
\hline $2703-7$ & B & Partial pressure of oxygen ( $\mathrm{PaO} 2)$ & 0 & 75 & $\mathrm{mmHg}$ & Low Partial pressure of oxygen \\
\hline $2703-7$ & $\mathrm{~B}$ & Partial pressure of oxygen ( $\mathrm{PaO} 2)$ & 100 & 1000 & $\mathrm{mmHg}$ & High Partial pressure of oxygen \\
\hline $19884-6$ & B & Partial pressure of carbon dioxide ( $\mathrm{PaCO} 2)$ & 38 & 42 & $\mathrm{mmHg}$ & Low Partial pressure of carbon dioxide \\
\hline $19884-6$ & B & Partial pressure of carbon dioxide ( $\mathrm{PaCO} 2)$ & 38 & 42 & $\mathrm{mmHg}$ & High Partial pressure of carbon dioxide \\
\hline $2744-1$ & B & Arterial blood pH & 0 & 7,38 & & Low Arterial blood pH \\
\hline $2744-1$ & B & Arterial blood pH & 7,42 & 10 & & High Arterial blood pH \\
\hline $59415-0$ & B & Oxygen saturation ( $\mathrm{SaO} 2$ ) & 94 & 100 & $\%$ & Low Oxygen saturation \\
\hline $59415-0$ & B & Oxygen saturation ( $\mathrm{SaO} 2)$ & 94 & 100 & $\%$ & High Oxygen saturation \\
\hline $1959-6$ & B & Bicarbonate - $(\mathrm{HCO} 3)$ & 22 & 28 & $\mathrm{mEq} / \mathrm{L}$ & Low Bicarbonate \\
\hline $1959-6$ & B & Bicarbonate - $(\mathrm{HCO} 3)$ & 22 & 28 & $\mathrm{mEq} / \mathrm{L}$ & High Bicarbonate \\
\hline
\end{tabular}

Figure 3: List of variables.

urea, blood creatinine, blood sodium and blood potassium.

How the alert engine works: The Alert engine receives and processes data from the Laboratory Information System (LIS) and the Health Information

System (HIS). Low or high levels of the above mentioned variables trigger an alert, and a warning message displays on the HIS system screen. (Figure 2).

The alert engine is a program created in $\mathrm{C} \sharp$ that contains the rules for triggering alerts. The alert engine receives patients' laboratory results from the Laboratory Information System (LIS) via HL7 v2.4 messages and then processes this information. If the engine detects a critical value in a patient's laboratory results, such as low or high levels of blood glucose, hematocrit, white blood cells, arterial blood gases, blood urea, blood creatinine, arterial sodium or arterial potassium, the alarm is triggered.

The algorithm works as follows: The system has a configuration table with the variable that we want to control, its maximum and minimum reference values and with messages to send in each case (see Figure 3)

The system has a SQL query routine whose parameters receives the LOINC code, sex and the laboratory value. This routine returns all alerts that must be displayed and send them to a function programmed in $\mathrm{C} \sharp$, with which the system builds the message alert in HL7 to be sent to the EHR.

The alarm sends a message that is displayed on the electronic health record (EHR) and is the first thing a physician or nurse sees when the patient's record is opened (Figure 2).

\section{Results}

The average age of the study population in both groups was 67.05 years, with the oldest patient 96 and the youngest 22 (Table 1 ).

Table 1: Age of sample population.

\begin{tabular}{lrrr}
\hline & Alert & Control & Both \\
\hline Total & 150 & 150 & 300 \\
Age max & 93.00 & 90.00 & 93.00 \\
Age min & 34.50 & 22.00 & 22.00 \\
Average age & 67.34 & 66.76 & 67.05 \\
\hline
\end{tabular}

Clinical laboratory risk was detected in $34.3 \%$ of the alert group patients, while in the control group, clinical laboratory risk was detected in $33.8 \%$ of the patients, a non-significant difference between the two groups, as shown in Table 2. The sensitivity was 0.99 and the specificity was 0.98 .

Table 2: Results alert group.

\begin{tabular}{lrr}
\hline Total & 147 & 145 \\
Undetected clinical laboratory risk & 130 & 131 \\
Detected clinical laboratory risk & 68 & 67 \\
\hline
\end{tabular}

Clinical laboratory risk was detected in $20.3 \%$ of the control group patients, while in the criterion standard, clinical laboratory risk was detected in $32 \%$ of the patients; the difference between the two groups was significant $(\mathrm{p}<0.001)$. 


\section{Discussion}

The results demonstrate that the clinical laboratory risk alert we built was of significant help. The rate of clinical laboratory risk detection was lower in the group with no alert system than in the group with an alert system $(20.3 \%$ versus $34.3 \%)$. The alert had a high sensitivity and specificity and this fact helped doctors to diagnose clinical laboratory risk. However, there was a bias in our method: Control group doctors knew that we were carrying out a research on the clinical laboratory status of patients in the unit and that they were being monitored. This might have affected their behavior and, consequently, the outcome of this research. Clinical laboratory risk in hospitalized patients is often undiagnosed. After thorough research, we have not found precedents of this tool being used in the healthcare industry. In the intensive care unit of our hospital, we observed that clinical laboratory risk was higher than we thought, so we considered some strategies to find a method to avoid this problem. Many times doctors worry about certain pathology a hospitalized patient may have and they underestimate complementary diagnostic aspects. 13. We think clinical laboratory alerts are useful to solve specific problems in a certain area, for a specific group of professionals or in a certain point in time. We think they cannot be used without any control. For example, in our hospital, intensive care physicians did not pay a great deal of attention to patients' clinical laboratory results and the alert was useful for this.

We designed a study on clinical laboratory alerts using interfaces with electronic and laboratory reports to collect information allowing alerts to be generated on possible clinical laboratory risks. In our study we observed that this kind of clinical laboratory alert makes the physician aware of possible clinical laboratory risk and decreases the patient's clinical laboratory risk. We think it is very important to use alerts, and in our study we managed to show their usefulness: Physicians using alerts could diagnose more problems than those who did not receive alerts. We highly recommend paying attention to the design of the system: It is important to avoid an excessive number of alerts on electronic clinical laboratory reports because the excess of information generates frustration in doctors, who may skip reading some useful information.

\section{References}

[1] Brieux HFM, Kaminker D, Campos F, Guillen S, Alejandris J, Luna D, et al. Nutritional Alert in hospitalized patients. Stud
Health Technol Inform. 2014;205:697-701.

[2] Casscells W, Schoenberger A, Graboys TB. Interpretation by Physicians of Clinical Laboratory Results. N Engl J Med. 1978 Nov 2;299(18):999-1001.

[3] Martíez I, Escayola J, Martínez-Espronceda M, Muñoz P, Trigo JD, Muñoz A, et al. Seamless Integration of ISO/IEEE11073 Personal Health Devices and ISO/EN13606 Electronic Health Records into an End-to-End Interoperable Solution. Telemed E-Health. 2010 Nov 18;16(10):993-1004.

[4] Shahangian S, Cohn RD, Gaunt EE, Krolak JM. System to Monitor a Portion of the Total Testing Process in Medical Clinics and Laboratories: Evaluation of a Split-Specimen Design. Clin Chem. 1999 Feb 1;45(2):269-80.

[5] System NA of E (US) and I of M (US) C on E and the HC, Reid PP, Compton WD, Grossman JH, Fanjiang G. Information and Communications Systems: The Backbone of the Health Care Delivery System. 2005 [cited 2016 Jan 18]; Available from: http://www.ncbi.nlm.nih.gov/books/NBK22862/

[6] Bakker J, Nijsten MW, Jansen TC. Clinical use of lactate monitoring in critically ill patients. Ann Intensive Care. 2013 May $10 ; 3: 12$.

[7] Lamprinakos GC, Asanin S, Broden T, Prestileo A, Fursse $\mathrm{J}$, Papadopoulos KA, et al. An integrated remote monitoring platform towards Telehealth and Telecare services interoperability. Inf Sci. 2015 Jul 1;308:23-37.

[8] Piniewski B, Muskens J, Estevez L, Carroll R, Cnossen R. Empowering Healthcare Patients with Smart Technology. Computer. 2010;43(7):27-34.

[9] IHE PCD Technical Committee. IHE Patient Care Device Technical Framework Supplement Alarm Communication Management (ACM) Trial Implementation [Internet]. IHE International, Inc; 2012. Available from: http://www . ihe.net/uploadedFiles/Documents/PCD/IHE_ PCD_Suppl_ACM_Rev1.3_TI_2012-08-16.pdf

[10] Jacobs J, Jones E, Gabella B, Spring B, Brownson R. Tools for Implementing an Evidence-Based Approach in Public Health Practice. Prev Chronic Dis [Internet]. 2012 Jun [cited 2016 Jan 19]; Available from: http://www.cdc.gov/pcd/issues/2012/ 11_0324.htm

[11] Herrera Rodrigo C, Tapia-Ruano Díaz-Quetcuti C, Buño Soto A, García Montes M. Actuación del laboratorio ante la obtención de valores críticos. Rev Lab Clínico. 2010 Apr;3(2):80-6.

[12] D G, María A, Solari S S, Lagos L M, Poggi M H, Sánchez P $\mathrm{T}$, et al. Aviso de valores de alerta por parte del laboratorio clínico en una red de salud universitaria. Rev Médica Chile. 2009 Sep;137(9):1137-44.

[13] Berner ES, Graber ML. Overconfidence as a Cause of Diagnostic Error in Medicine. Am J Med. 2008 May;121(5, Supplement):S2-23. 